\title{
俞
}

\section{Guidelines on setting the target minute ventilation in Adaptive Support Ventilation}

Jean-Michel Arnal MD ${ }^{1}$, Ehab Daoud MD ${ }^{2}$

DOI: https://doi.org/10.53097/JMV.10029

Cite: Arnal JM, Daoud EG. Guidelines on setting the target minute ventilation in Adaptive Support Ventilation. J Mech Vent 2021; 2(3):80-85.

\section{Abstract}

Adaptive Support Ventilation (ASV) is a fully closed loop ventilation where the operator input the desired $\mathrm{PEEP}_{\text {, FiO }}$ and the target minute ventilation (MV) expressed as a percentage according to ideal body weight. The ventilator selects the target respiratory pattern (tidal volume, respiratory rate, and inspiratory time) based on the observed respiratory mechanics.

However, there are no published guidelines on settings and adjusting the target MV in different disease states during ASV ventilation.

INTELLiVENT-ASV, is the new generation modified algorithm of ASV, has made this issue much easier and simpler as the operator inputs a desired range of the end tidal exhaled carbon dioxide, and oxygen saturation and the algorithm will adjust the minute ventilation percentage as well as PEEP and $\mathrm{FiO}_{2}$ automatically to stay within that range.

In this article we describe some evidence-based guidelines on how to set and adjust the target MV in various clinical conditions.

Keywords: ASV, INTELLiVENT-ASV, Closed loop ventilation, End tidal $\mathrm{CO}_{2}, \mathrm{ARDS}, \mathrm{COPD}$, Respiratory failure

Authors

1 Jean-Michel Arnal: Affiliated with the Service de Re'animation Polyvalente, Hôpital Sainte Musse, Toulon, France.

Director of the department of Medical Research, Hamilton Medical, Bonaduz, Switzerland.

2 Ehab G. Daoud: Professor of medicine, JABSOM, University of Hawaii

Director of respiratory care program, Kapiolani Community College, Hawaii, USA

Corresponding author: ehab_daoud@hotmail.com

Conflict of interest/Disclosures:

Funding: None

Journal of Mechanical Ventilation 2021 Volume 2, Issue 3

This open-access article is distributed under the terms of the Creative Commons Attribution Non-Commercial License (CC BY-NC) (http://creativecommons. $\mathrm{org} /$ licenses/by-nc/4.0/), which permits reuse, distribution and reproduction of the article, provided that the original work is properly cited and the reuse is restricted to 


\section{Introduction}

ASV and the newer generation INTELLiVENT-ASV are fully automated closed loop ventilator modes that use the optimal or intelligent targeting scheme. ${ }^{1}$ The algorithm used can ventilate both passive and active patients either in full continuous mandatory pressure-controlled mode, intermittent mandatory pressure-controlled mode or continuous spontaneous pressure support mode depending on patients' inspiratory effort and rate. ${ }^{2}$

After logging the patient's gender and height to determine the ideal body weight (IBW), and after choosing the percent minute ventilation $(\% \mathrm{MV})$, the ventilator monitors the expiratory time constant (RCexp) algorithm determines the best combination of respiratory rate (RR), tidal volume (VT), inspiratory pressure (DP), inspiratory and expiratory times to minimize the work and the force of breathing in a protective lung ventilation based on the Otis and Mead equations, respectively. 3,4

ASV and INTELLiVENT-ASV have proved multiple benefits in patients with respiratory failure from different etiologies. They have proven beneficial in shortening weaning times and timing on mechanical ventilation. ${ }^{5,6,7,8,9,10} \mathrm{ASV}$ has shown many benefits in different kinds of respiratory failure. ${ }^{11,12,13,14}$ Similarly, both ASV and INTELLiVENT-ASV have proven beneficial in terms of efficacy and safety. ${ }^{15,16,17,18}$

However there have been no guidelines on the settings to initiate ASV.

\section{Target minute volume in ASV}

When using ASV, target MV is expressed in percentage. A target MV set at $100 \%$ means that the MV will be 100 times IBW, which is the normal MV requirement to achieve a normal $\mathrm{PaCO} 2$ in a patient with normal $\mathrm{CO} 2$ production, cardiac output, and ventilation/perfusion ratio.

In passive patients, ASV provide an adaptive pressurecontrolled mode. In this condition, the actual MV match the target MV set by the user. Therefore, the target MV should be set and adjusted according to $\mathrm{PaCO} 2$ mainly.

In spontaneous breathing patients, ASV provides an adaptive pressure support mode. In this condition, the target MV is different from the actual minute volume. Target MV is a minimum, but the actual MV is usually higher than the target MV. ASV algorithm uses the target MV to determine an optimum VT and adjust pressure support to achieve this VT. If the user increases the target MV, this will increase the optimum VT and the ventilator will increase PS. Conversely, decreasing target MV will decrease PS. However, the actual pressure support that is selected depends both on the target minute volume and on the patient's effort. If the patient's effort increases, PS will decrease to keep VT at the optimum value.

\section{ASV settings}

To initiate ASV, there are mandatory settings to be dialed by the clinicians. Those include the patients' gender and age, $\% \mathrm{MV}, \mathrm{FiO} 2, \mathrm{PEEP}$, expiratory time sensitivity (ETS): the percent flow decay in the spontaneous breath to cycle from inspiration to expiration, and finally the ramp rise time. All those settings except the \%MV are like conventional ventilatory modes and are described elsewhere. ${ }^{19,20}$

Several factors are included in the decision of a choice of $\% \mathrm{MV}$. In passive patients, the selection is mainly based on the lung condition which determine the ventilation/perfusion, the metabolism (fever, sepsis, hypothermia) which influences the $\mathrm{CO}_{2}$ production, and the use of a humidity moisture exchanger (HME) which increases the artificial dead space. Therefore, patients with disturbed ventilation/perfusion ratio, increased $\mathrm{CO}_{2}$ production, or increased artificial dead space require a higher target $\mathrm{MV}$ to achieve $\mathrm{CO}_{2}$ elimination. Study in many passive ICU patients have demonstrated that normal lung patients can be managed with a \%MV set around $110 \%$ while patients with ARDS and COPD require higher \%MV around $130 \%{ }^{21}$

These values can be used as references for initial settings and must be adjusted individually. (Table 1) $\mathrm{PaCO}_{2}$ is measured after 20 minutes. If $\mathrm{PaCO}_{2}$ is higher than the clinician target, an increase of $\% \mathrm{MV}$ by $10 \%$ usually decreases $\mathrm{PaCO}_{2}$ by $5-10$ $\mathrm{mm}$ Hg. Target \%MV above $200 \%$ is very unusual. It may occur if IBW was underestimated, or in case of large dead space (HME or high alveolar dead space due to high PEEP).

In spontaneous breathing patients, $\% \mathrm{MV}$ is no more adjusted according to $\mathrm{PaCO} 2$ but according to patient effort. The initial settings are like passive patients. If patient has a high respiratory rate and/or is doing lot of effort to breath, then ventilation support should be increased by increasing the $\% \mathrm{MV}$ by $20 \%$. If the increase in ventilation support does not affect the patient effort and respiratory rate, clinician should suspect a high respiratory drive due to metabolic acidosis, pain, or anxiety. In such case, changing ventilation support will not affect the patient effort.

\section{Breath pattern selected}

As mentioned above, the ASV algorithm picks a combination of respiratory rate, tidal volume, inspiratory pressure, and inspiratory and expiratory time in a protective lung ventilation to minimize lung injury and reduce the work of breathing in accordance with the patients' respiratory mechanics. 
Table 2 and figure 1 show the ventilator target minute ventilation ( $\dot{\mathrm{Ve}})$, tidal volume depending on the dialed \%MV in three different medical conditions: Normal respiratory system (Normal), Restrictive respiratory mechanics (ARDS), and Obstructive respiratory disease (COPD) in a male patient with IBW of $70 \mathrm{~kg}$ based on Arnal and colleagues' parameters of simulation. ${ }^{22}$

Interestingly, while VT/IBW selected by the ASV algorithm varies according to lung condition, driving pressure is kept in safe ranges (around 10-12 $\mathrm{cmH}_{2} \mathrm{O}$ ) in all lung conditions. ${ }^{23}$ However, clinician must still monitor VT/IBW, Pplat and $\Delta \mathrm{P}$ to make sure that the breath pattern selected is lung protective.

\section{INTELLiVENT-ASV}

INTELLiVENT-ASV is an advanced ventilation mode, based on the ASV mode, to automatically regulate $\mathrm{CO} 2$ elimination and oxygenation for both passive and active patients, based on both physiologic data from the patient and clinician-set targets. With this mode, the clinician sets targets for PetCO and $\mathrm{SpO}_{2}$ for the patient. INTELLiVENT-ASV then automates management of the controls for $\mathrm{CO}_{2}$ elimination
(\%MinVol), and oxygenation (PEEP and Oxygen) based on these targets and on the physiologic input from the patient $\left(\mathrm{PetCO}_{2}\right.$ and $\left.\mathrm{SpO}_{2}\right)$.

INTELLiVENT-ASV has made the initial settings and the continuous adjustments more automated and much simpler. In addition to the usual input in ASV, INTELLiVENT-ASV have both a manual option for setting (exactly as ASV) and automatic option.

First, the operator has the choice of choosing between three different patient conditions: chronic hypercapnia, brain injury and ARDS. When the operator elects to choose the automatic option for ventilation settings, a target $\mathrm{PetCO}_{2}$ is chosen, and the ventilator will adjust the $\% \mathrm{MV}$ (respiratory rate and tidal volume targets) automatically to keep the patient within that target. When chosen, the automatic oxygenation setting will adjust the $\mathrm{FiO}_{2}$ and PEEP according to target $\mathrm{SpO}_{2}$. The operator can set high and low limits for all targets that the ventilator would not go above or below.

\begin{tabular}{|l|l|l|l|l|l|}
\hline Lung condition & $\begin{array}{l}\text { Initial \%MV } \\
\text { setting* }\end{array}$ & $\begin{array}{l}\text { Adjustment in } \\
\text { passive patients } \\
\text { passive patients }\end{array}$ & $\begin{array}{l}\text { Adjustment step in } \\
\text { spontaneous } \\
\text { breathing patients } \\
\text { breathing patients } \\
\text { spontaneous }\end{array}$ \\
\cline { 1 - 2 } Normal lung & $100 \%$ & $\begin{array}{l}\text { According to } \\
\text { PaCO }_{2}\end{array}$ & $\pm 10 \%$ & $\begin{array}{l}\text { According to } \\
\text { patient's effort } \\
\text { and RR }\end{array}$ & $\pm 20 \%$ \\
\hline ARDS & $130 \%$ & $130 \%$ & & \\
\hline
\end{tabular}

* Clinician may add 10\% in case of HME use.

Table 1: suggested initial settings of percent minute ventilation and their subsequent adjustment in three different clinical scenarios.

\begin{tabular}{|l|l|l|l|l|l|l|}
\hline & $50 \%$ & $100 \%$ & $150 \%$ & $200 \%$ & $250 \%$ & $300 \%$ \\
\hline Normal & $\begin{array}{l}430(6.1 \\
\mathrm{ml} / \mathrm{kg})\end{array}$ & $\begin{array}{l}513(7.3 \\
\text { ML/KG) }\end{array}$ & $\begin{array}{l}580(8.3 \\
\mathrm{ML} / \mathrm{KG})\end{array}$ & $638(9.1 \mathrm{ml} / \mathrm{kg})$ & $689(9.8 \mathrm{ml} / \mathrm{kg})$ & $736(10.5 \mathrm{ml} / \mathrm{kg})$ \\
\hline ARDS & $\begin{array}{l}363(5.2 \\
\mathrm{ml} / \mathrm{kg})\end{array}$ & $\begin{array}{l}406(5.8 \\
\mathrm{ml} / \mathrm{kg})\end{array}$ & $443(6.3 \mathrm{ml} / \mathrm{kg})$ & $475(6.78 \mathrm{ml} / \mathrm{kg})$ & $505(7.2 \mathrm{ml} / \mathrm{kg})$ & $532(7.6 \mathrm{ml} / \mathrm{kg})$ \\
\hline COPD & $\begin{array}{l}578(8.2 \\
\mathrm{ml} / \mathrm{kg})\end{array}$ & $\begin{array}{l}734(10.5 \\
\mathrm{ml} / \mathrm{kg})\end{array}$ & $920(13 \mathrm{ml} / \mathrm{kg})$ & $\begin{array}{l}1170(16.7 \\
\mathrm{ml} / \mathrm{kg})\end{array}$ & $\begin{array}{l}1539(21.9 \\
\mathrm{ml} / \mathrm{kg})\end{array}$ & $\begin{array}{l}1539(21.9 \\
\mathrm{ml} / \mathrm{kg})\end{array}$ \\
\hline
\end{tabular}

Table 2: Target tidal volume and minute ventilation according to set \%MV in three different clinical scenarios. 


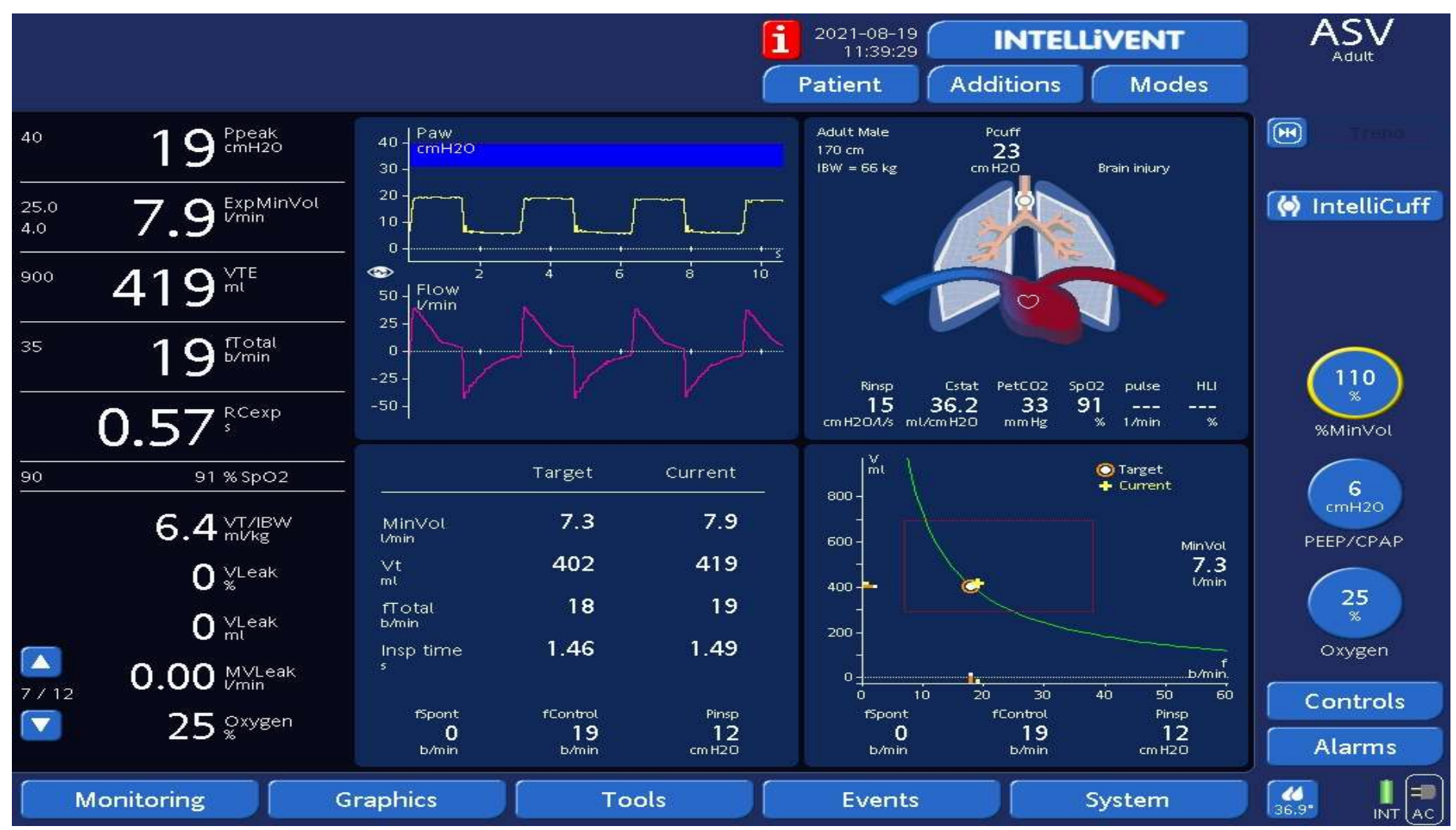

Figure 1: screen shot for ASV showing the ASV graph and monitor in a passive patient with low respiratory compliance of 36 $\mathrm{ml} / \mathrm{cmH}_{2} \mathrm{O}$, resistance $15 \mathrm{cmH}_{2} \mathrm{O} / \mathrm{L} / \mathrm{s}$, Rexp (expiratory time constant) of 0.57 seconds.

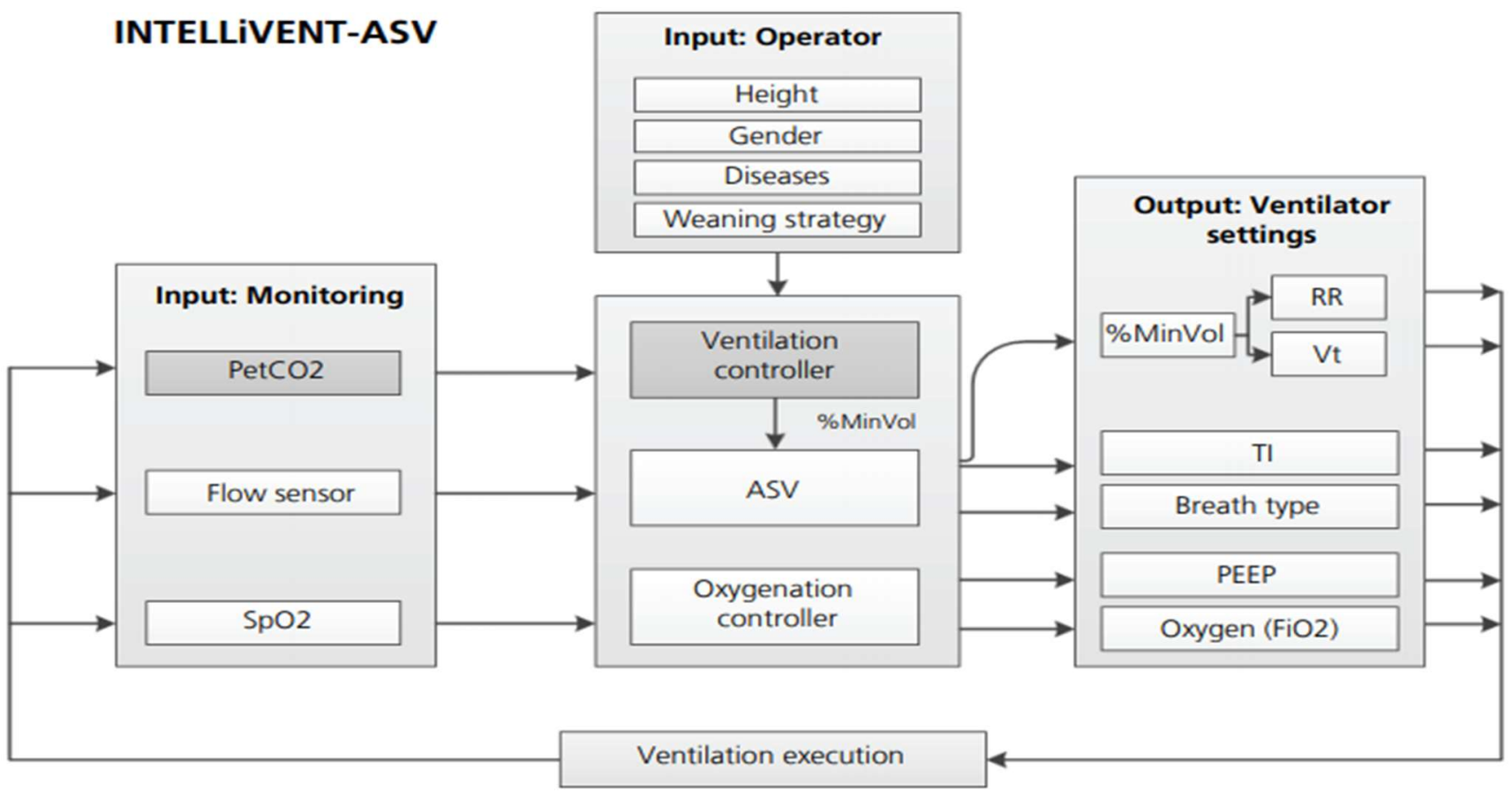

Figure 2: shows the schematic workflow for INTELLiVENT-ASV. From Hamilton Medical with permissio 


\section{Discussion}

Choosing the mode of ventilator and the initial settings could be a challenging task. ${ }^{24}$ The initial settings have to take into accounts multiple factors. The degree of altered ventilation and oxygenation, the state of altered respiratory mechanics, the patients' metabolic state, the patients' work of breathing and condition of the respiratory muscles.

Closed loop ventilator modes like ASV and INTELLiVENTASV had simplified this task and shown to decrease the burden on clinicians by reducing the amount of ventilator and parameter changes, ${ }^{15,25}$ while efficiently and safely choosing the respiratory parameters of oxygenation and ventilation. $15,16,17,18$

In this article, we concentrate our efforts on the \%MV being the unique feature of ASV and INTELLiVENT-ASV. Though other parameters like FiO2 and PEEP are especially important, setting PEEP in ASV is not any different than other conventional modes of ventilation. Setting PEEP on INTELLiVENT-ASV can be done automatically by the ventilator if the automatic option is chosen.

To our knowledge, there has not been any prospective or retrospective studies comparing different settings of both modes. A study by Mireles-Cabodevila and colleagues ${ }^{26}$ have shown that clinicians and ASV have chosen similar settings in ASV in five different simulated clinical scenarios except for asthma.

Our suggestions are based on the targeted minute ventilation with its two components the respiratory rate and tidal volume chosen by the ventilator for each \%MV chosen by the clinician in ASV. Those suggestions take in account the initial tidal volume/IBW and the lowest effective inspiratory pressures. Without doubt those settings might not suit every single patient and bedside clinical experience is paramount. We also suggest continuous monitoring of the oxygenation and ventilation parameters with $\mathrm{SpO} 2, \mathrm{PetCO} 2$ (a volumetric one with capability of measuring alveolar minute ventilation, dead space, VD/VT, and carbon dioxide production VCO2 will be more favorable). Monitoring the respiratory mechanics (total respiratory, lung, and chest wall compliance and resistance) could also be very helpful for initial settings and continuous adjustments.

Our suggestion for INTELLiVENT-ASV, is to input the clinical condition if known, and to choose the automatic selection of \%MV after choosing a safe range of the PetCO2 especially if the patients' baseline $\mathrm{PaCO} 2$ and the difference between the $\mathrm{PaCO} 2$ and the PetCO2.

\section{Conclusion}

Thanks to the advanced technology and the new innovations of mechanical ventilation closed loop modes, choosing a mode has never been easier. We tried to set some guidelines on how to choose the initial settings of ASV and INTELLiVENTASV.

\section{References}

1. Chatburn RL, Mireles-Cabodevila E. Closed loop control of mechanical ventilation: description and classification of targeting schemes. Respir Care 2011; 56(1)85-102.

2. Fernández J, Miguelena D, Mulett, H, et al. Adaptive support ventilation: State of the art review. Indian J Crit Care Med 2013; 17(1):16-22.2.

3. Koca U, Demirdoven BT. Adaptive Support Ventilation. J Respir Dis Med 2020; 2:1-4.

4. Otis AB, Fenn WO, Rahn H. Mechanics of breathing in man. J Appl Physiol 1950; 2:592-607.

5. Zhu F, Gomersall CD, Ng SK., et al. A randomized controlled trial of adaptive support ventilation mode to wean patients after fast-track cardiac valvular surgery.

Anesthesiology 2015; 122(4):832-840.

6. Yazdannik A, Zarei H, Massoumi G. Comparing the effects of adaptive support ventilation and synchronized intermittent mandatory ventilation on intubation duration and hospital stay after coronary artery bypass graft surgery. Iranian Journal of Nursing and Midwifery Research Iran J Nurs Midwifery Res 2016; 21(2):207-212.

7. Tam MK, Wong WT, Gomersall, CD, et al. A randomized controlled trial of 2 protocols for weaning cardiac surgical patients receiving adaptive support ventilation. J Crit Care 2016; 33:163-168.

8. Lellouche F, Bouchard P, Simard S, et al. Evaluation of fully automated ventilation: a randomized controlled study in post-cardiac surgery patients. Intensive Care Med 2013; 39(3): 463-471.

9. Gruber PC, Gomersall CD, Leung P, et al. Randomized controlled trial comparing adaptive-support ventilation with pressure-regulated volume-controlled ventilation with automode in weaning patients after cardiac surgery. Anesthesiology 2008; 109(1): 81-87. 
10. Fathi H M, Osman DM. Weaning of chronic obstructive pulmonary disease patients after coronary artery bypass graft surgery. Res Opin Anesth Intensive Care 2018; 5:147-153.

11. Kirakli C, Naz I, Ediboglu O, et al. A randomized controlled trial comparing the ventilation duration between adaptive support ventilation and pressure assist/control ventilation in medical patients in the ICU. Chest 2015; 147(6):1503-1509.

12. Ghodrati M, Pournajafian A, Khatibi A, et al. Comparing the effect of adaptive support ventilation (ASV) and synchronized intermittent mandatory ventilation (SIMV) on respiratory parameters in neurosurgical ICU Patients. Anesth Pain Med 2016; 2;6(6):e40368.

13. El-Shenawy OM, Metwally MM, Abdel-Mabboud AE, et al. Adaptive support ventilation versus synchronized intermittent mandatory ventilation in patients with chronic obstructive pulmonary disease. J Curr Med Res Pract 2018; $3: 1-5$.

14. Sulemanji D, Marchese A, Garbarini P, et al. Adaptive support ventilation: An appropriate mechanical ventilation strategy for acute respiratory distress syndrome?

Anesthesiology 2009; 111:863-870.

15. Botta M, Wenstedt EFE, Tsonas AM, et al. Effectiveness, safety and efficacy of INTELLiVENT-adaptive support ventilation, a closed-loop ventilation mode for use in ICU patients - a systematic review. Expert Rev Respir Med 2021; 31:1-11.

16. Arnal JM, Wysocki M, Novotni D, et al. Safety and efficacy of a fully closed-loop control ventilation (IntelliVentASV $\left.{ }^{\circledR}\right)$ in sedated ICU patients with acute respiratory failure: a prospective randomized crossover study. Intensive Care Med 2012; 38(5):781-787.

17. Arnal JM, Garnero A, Novonti D, et al. Feasibility study on full closed-loop control ventilation (IntelliVent-ASVTM) in ICU patients with acute respiratory failure: a prospective observational comparative study. Crit Care 2013; 17(5):R196.

18. Bialais E, Wittebole X, Vignaux L, et al. Closed-loop ventilation mode (IntelliVent ${ }^{\circledR}-\mathrm{ASV}$ ) in intensive care unit: a randomized trial. Minerva Anestesiol 2016; 82(6):657-668.

19. Daoud EG, Shimabukuro R. Mechanical ventilation for the non-critical care trained practitioner. Part 1. J Mech Vent 2020; 1(2):39-51.

20. Sahetya SK, Goligher EC, Brower RG. Fifty Years of Research in ARDS. Setting Positive End-Expiratory Pressure in Acute Respiratory Distress Syndrome. Am J Respir Crit Care Med. 2017; 1;195(11):1429-1438.

21. Arnal JM, Wysocki M, Nafati C, et al. Automatic selection of breathing pattern using adaptive support ventilation. Intensive Care Med 2008; 34(1):75-81.

22. Arnal JM, Garnero A, Saoli M, et al. Parameters for simulation of adult subjects during mechanical ventilation. Respir Care 2018; 63(2):158-168.

23. Arnal JM, Saoli M, Garnero A. Airway and transpulmonary driving pressures and mechanical powers selected by INTELLiVENT-ASV in passive, mechanically ventilated ICU patients. Heart Lung 2020; 49(4):427-434.

24. Mireles-Cabodevila E, Hatipoğlu U, Chatburn RL. A rational framework for selecting modes of ventilation. Respir Care 2013; 58(2):348-366.

25. Wheatley D, Young, K. Adaptive support ventilation. What is it? Beneficial or not? J Mech Vent 2020; 2(1):34-44.

26. Mireles-Cabodevila E, Diaz-Guzman E, Arroliga AC, et al. Human versus computer controlled selection of ventilator settings: An evaluation of adaptive support ventilation and mid-frequency ventilation. Crit Care Res Pract 2012: 204314.

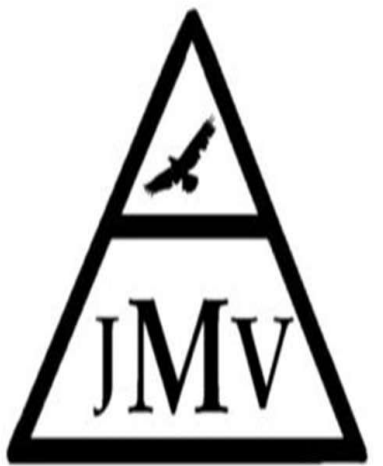

Journal of Mechanical Ventilation

Submit a manuscript

https://www.journalmechanicalventilation .com/submit-a-manuscript/

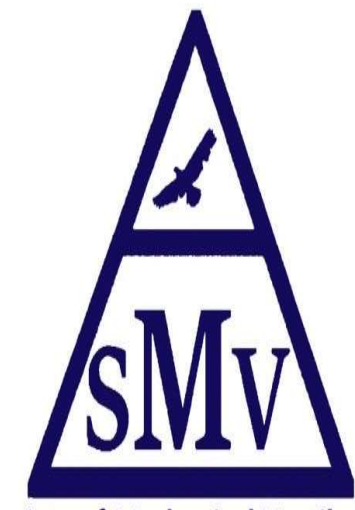

Society of Mechanical Ventilation /membership/ 